\title{
A Resilience Approach to Defence Critical Infrastructure
}

\author{
Cherylne Fleming \\ Defence Science and Technology Group \\ Email: Cherylne.fleming@dsto.defence.gov.au
}

\begin{abstract}
Defence is critically dependent on its own and national infrastructure for energy, water, information, transport, telecommunications and emergency services. The degree of interdependence between defence and national infrastructure varies across these basic services. This combination creates a very complex dynamic system. Review of Defence locations usually start with the logical system boundary the fence that surrounds the site. Infrastructure considerations which link and support the sites, these are viewed as external to Defence and as such beyond the Defence Organisational influence, missing the strong interdependency found "over the fence". This paper describes an approach to understand the dependencies and fragilities which impact defence resilience.
\end{abstract}

This resilience approach identifies potential impacts on defence capability, points/areas of failure when data sets are combined from both internal and external sources. A number of themes emerged from the analysis including strategic shocks, chronic stressors (e.g. perpetually under-resourced areas), divergent views (e.g. alternative lines of command / priorities), vulnerabilities, graceful degradation (e.g. aging assets) and future plans.

In order to achieve this, we extracted data from many Defence inputs such as: the industry policy statements, estate management, logistics supply chains and the Force Structure Review / force mix assumptions and scenarios. In addition, external data was accessed from sources such as Northern Territory government, Australian Bureau of Statistics, Attorney Generals Department / Critical Infrastructure Protection Modelling Agency, Engineers Australia, and Geoscience Australia. This dataset was used to cross reference the subject matter expert (SME) views collected at workshops and via surveys. This allowed SMEs to provide the impact the historical events that impacted Defence activities, and for those impacts to be categorised into themes, case studies and exemplars.

This work demonstrates the impact of critical infrastructure on Defence capability, and highlights the importance of a resilient infrastructure. Actions that bring about change in a specific area often lead to unanticipated and potentially unwanted consequences elsewhere. Treating resilience as a component of the defence system recognises that our world is changing and that changes occur often in an interlinked way.

Keywords: Decision support systems, critical infrastructure, resilience 


\section{INTRODUCTION}

Critical infrastructure (CI) ${ }^{l}$ underpins the functioning of Australian society and economy. It delivers or facilitates "...services essential to our daily lives, such as power, water, health services, communications and banking"." The resilience of Australian CI is therefore integral to the prosperity of the nation and important to National Security. Defence is currently coming to terms with the extent of its reliance on CI particularly in relation to its operations. Noting that most CI in Australia is either privately owned and operated or run on a commercial basis by government, there are commercial incentives to ensure its resilience. The Attorney Generals Department has published a Critical Infrastructure Resilience Strategy (2014) which acknowledges a shift in perspective from its earlier protective approach, to one that acknowledges that disruptions will occur. The ability to mitigate harmful effects on CI and focus on the nation's ability to recover is a useful step forward.

Resilience is commonly viewed as the ability of a system to recover or continue after an event. Resilience and risk are often coupled together. So while the term 'resilience' is not necessarily a 'systems' term, we do talk about resilient systems and systemic risks. Internal reviews of Defence sites usually start with the logical system boundary, that is, the physical boundary that surrounds the site ${ }^{3}$. Infrastructure links onto the site are viewed as part of the external system and outside the Australian Defence Force (ADF) area of interest or influence. Such a view ignores important dependencies. This paper explicitly focuses on Defence's dependence on national CI, because these fragilities directly impact Defence's operational resilience.

\section{APPROACH}

Resilience is then seen as persistence, the ability of a system to function over time in the presence of disruptions. Understanding the activities defence undertakes and the internal and external events that can impact those activities provides a useful foundation to discuss the resilience of a region of interest or particular defence site. In order to examine the impact of CI disruption events on defence activities, historical evidence was sought. Event duration and impact were the starting points in our approach (Ali 2014, Meadows 2008). The initial work began with scoping the extant documents (Figure 1) this was followed by undertaking a survey of SME and then analysis to identify correlations and patterns of interest (Creswell 2009). Some 400 documents were identified and assessed (Figure 1). In all of these sources, the focus was on identifying the timeframes and impacts on Defence and events of interest. The study reviewed the documents for independence, relevance, timeframe, and evidence of impacts at Defence sites.

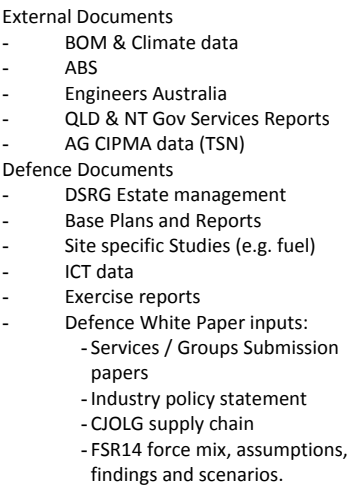

Figure 1. Extant documents.

The SMEs were surveyed to identify their experiences of CI disruptions (shown in Table 1) and their effects on Defence. Many factors were taken into consideration (Punch 2005, Creswell 2009, Berry 2007, Ali 2011) in the engagement with SME six key considerations were made in the data collection approaches:

- Identification of system flows including limits, known impacts and local practices

- Survey (online) SME views

- Length -surveys should take 5 minutes or less to complete.

- Format - drop box / set choice options followed by scaled ratings using the same scale as existing Defence Estate and broader departmental policy and plans.

- Provided Value - The offer of a copy of the final results and reports and any recommendations was seen as an incentive by participants.

o Participants Selection - individuals who hold / have held positions with potential relevant experiences.

- Reminders Sent - by the base/local chain of command or their known delegate. For this survey two reminder emails were sent (at different time of day and day of the week).

- Workshops CBR \& Darwin / Townsville

- Interviews and site visits

\footnotetext{
${ }^{1}$ A definition for Critical Infrastructure may be found at http://www.tisn.gov.au/Documents/CIPMA-flyer.PDF

${ }^{2}$ http://www.ag.gov.au/NationalSecurity/InfrastructureResilience/Pages/CriticallinfrastructureProgramforModellingandAnalysisCIPMA.aspx

${ }^{3}$ The term "Sites" is used to here collectively to refer to bases, office building to exercise areas, and the wide variety of other areas used for Defence purposes. Also for defence purposes, Defence deployable equipment will be considered as part of Defence $\mathrm{Cl}$, for example mobile generators.
} 
Table 1. Threat Types

\begin{tabular}{|l|l|l|}
\hline Threat Type & External & Internal \\
\hline Natural & $\begin{array}{l}\text { Earthquake flood tsunami tropical storm drought } \\
\text { disease }\end{array}$ & N/A \\
\hline Deliberate & Terrorism, crime or espionage & Employee sabotage, strike action \\
\hline Accidental & Cut cable or water pipe & Error loss or improper use of equipment, improper maintenance, fire, poisoning \\
\hline
\end{tabular}

All of the SME were APS or serving ADF personal. Their selection for participation was based on their experience, local/site knowledge, and/or position held within the organisation. The SME group were representative of the site, e.g. where the site was dominantly Army, most responses were from that Service. Additional SME input was sought from Canberra sites, due to the 3 year posting cycles of the Services it was necessary to seek these SME perspectives to address the full five years of interest to the study. It was acknowledged during this work, that the likelihood or probability element in the risk equation can be problematic when frequency data are limited (or unavailable). This is why the data obtained from SMEs via the survey was so critical to the success of this work, identifying key dates and types of events. The SME could document what the impacts were, and they also assisted in the workshops in identifying patterns where CI disruption has impacted on Defence and is likely to do so again. Finally, the correlation with external quantitative data sets, for example from the BOM, allowed the results to be considered in future decision making.

\section{RESULTS}

The results of the document analysis confirmed that Defence CI impacts had occurred across all of the six CI areas of interest. However as most of the documents were not written from a CI, risk or resilience perspective they were useful only in identifying events and collaborating SME perspectives. Two noteworthy aspects encountered in the analysis of these documents were:

- The constant changes to capability and upgrading of CI across various sites meant that a clear, current picture was difficult to determine without visiting the site of interest; and

- The multiple reports of the same event in disparate documents - this clumping of significant events provided lots of collaborating evidence, particularly around significant weather events but also skewed the distribution of reported events.

Steps were taken to preclude experimental artefacts and ambiguities, and increase participant response rates (Punch 2005, Creswell 2009, Berry 2007, Ali 2011). The approach to the survey was to seek actual experiences from SMEs at the sites of interest. The survey participants responded with over 89\% (combined from Townsville and Darwin regions). By way of comparison internal surveys (i.e. employee surveys) generally have a much higher response rate than external surveys (i.e. customer satisfaction). Internal surveys will generally receive a 30-40\% response rate or more on average, compared to an average $10-15 \%$ response rate for external surveys (Punch 2005). Response rates above 85\% (about 43 responses for every 50 invitations sent) only occur when the respondent population is motivated and the survey is well-executed. The high response rate was seen as evidence of individuals wanting to ensure their experiences were recorded.

The internal and external document review provided the means to cross check the views of SMEs captured in the surveys. Only those events which could be correlated by an independent document where included in our data set. These multiple sources were used to understand the event Ali (2014), its character (duration etc.) and its impacts, provided a strong basis for further analysis Meadows 2008, Mingers and Rosenhead 2004). The SME survey data provided understanding of the Defence impacts and the types of events which had impacted Defence sites (Figure 2). The six CIPMA CI areas of interest are energy which is further subdivided into electricity and liquid fuels; water / waste water; health services; communications (both voice and data); transportation and food.

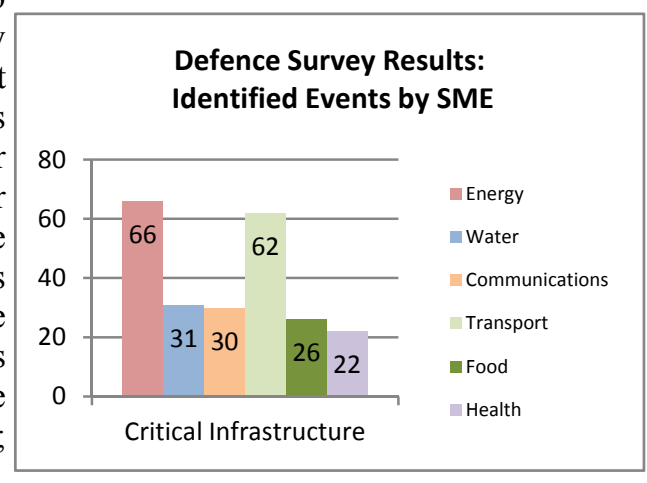

Figure 2. SME identified Events by Critical Infrastructure using the six CIPMA categories.

SMEs also provided data on the severity of events which have impacted Defence sites (Figure 3). The term Capability Factors (CF) is used to describe the potential impact an event has on Defence Capability. These capability factors have a scale of one to five, with CF1 as the highest - with all defence activities stopped. An example of a CF1 event might be a severe tropical cyclone. It is expected that a CF1 event would impact 
several regional sites. By contrast, CF5 events minimally impact defence activities, and include such events as road works requiring alternative site access. These CF5 events were generally not reported by the SMEs in this survey. Some events, such as a severe tropical cyclone, were recorded by multiple SMEs across several sites as CF1. These entries were treated as a set of data points for a significant CF1 regional event but their impact was still reported at each site.

The SMEs provided examples of many natural and accidental events (Table 1). For example significant numbers of ADF members arriving for exercises and the impact, with the influx of rental vehicles, this had with the local food (e.g. ADF acquiring all local stores of bread and milk) and fuel with local providers stocks off base also impacted. This example even stressed the waste water arrangements on base. This impact on the local community and ADF members in the exercise was not recorded in the exercise report, but rather reported against the base management plan. The local system resilience both on and off base was stressed by the exercise. Indeed even the Exercise objectives were limited due to the limits of CI. This shows the relationship between the surrounding infrastructure and defence activities. In addition it illustrates the internal disconnects in planning for exercises and in base plans, with their different reporting chains.

SME Survey Results: Identified Events by Site

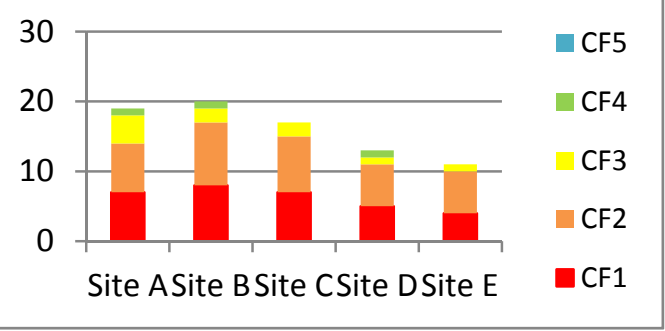

Figure 3. Number of Events described by Site from SMEs.

ADF members, like the rest of the community, need to transit from their homes to their work place. By combining the population data from the ABS with the Defence data, likely transit information showed some of the difficulties encountered during events, like a flood. This relates to defence resilience, as without defence personnel, Defence tasks are unable to be achieved. In Figure 4 both the journey to work for Defence employees and number of employees transiting from each of these suburbs is shown. Many defence

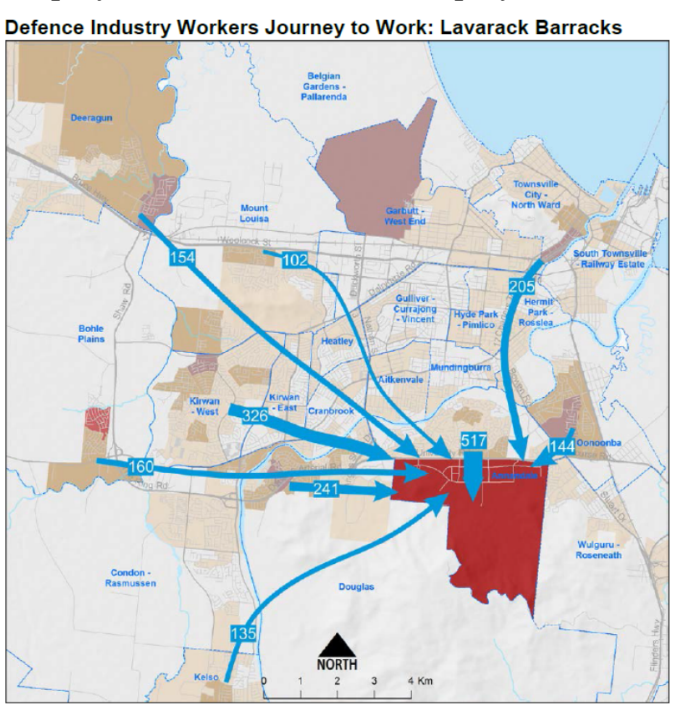

Figure 4. "Defence Industry" workers journey to work: Lavarack Barracks.

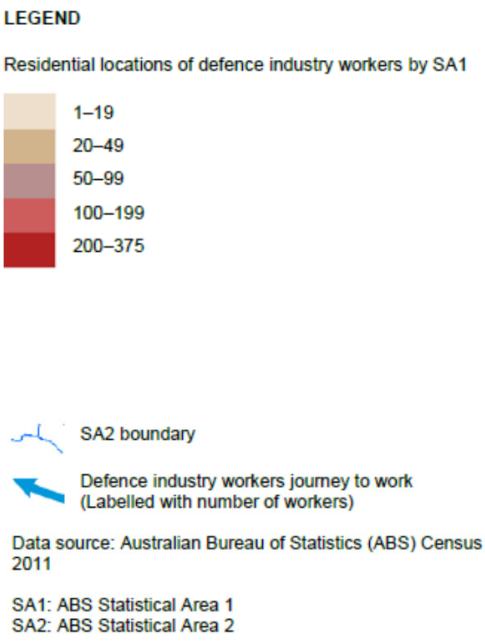
employees travel to Lavarack Barracks and RAAF Base Townsville from outer suburbs with newer housing stock such as Kirwan, Burdell, Douglas, Bohle Plains and Kelso. The distance between housing and work is a consideration; however the propensity of the area and road network to flood is a consideration which with impacts on Defences ability to undertake tasks.

\section{DISCUSSION}

The work focused on identifying the different types of CI disruptions or events that potentially impact on Defence resilience. Several such points/areas of vulnerability were found. A set of themes emerged from the analysis:

- Strategic Shocks are the risks which are low probability high impact events - e.g. Cyclone Tracey

- Divergent views are often produced from a bi-polar funding model, where different elements of the system have competing or non-complementary aims.

- Chronic Stressors were identified when over time the same minor/small - 'niggle' impacted successful completion of the task i.e. the implications on ADF training and readiness when the grass is not mown at a live fire range. Chronic stressors are typified as perpetually under resourced areas which appear to be 
invisible to the organisational reporting chains.

- Graceful degradation describes the situation or set of risks where the capability is planned to be replaced and is planned to gradually run down on the assumption that it will be shortly replaced and maintenance efforts are not keeping pace with degradation and aging of the capability, across a spectrum of infrastructure from defence equipment to site specific physical infrastructure.

Defence has a well-established risk management culture. Defence sites have required reporting on risks and risk mitigation plans. However risks can be especially difficult to measure in situations where local or site specific considerations are divergent from organisational directives. The organisational principle may be sound, however difficult to implement due to for example environmental considerations. These situations can create disconnects in reporting chains and local or temporary work-arounds (which over time become the local practice). No guarantee exists that everyone perceives the same risk the same way. Identification of an event by SME represented a qualitative perception which needed to be verified with our independent quantitative data. Any particular SME tended to report the most significant events encountered by that individual, such as severe tropical cyclones. By taking the broadest set of evidence available to the team, the themes identified represent the dynamics, patterns and cycles of the CI at the defence sites. The resultant case studies provided insights into how the events reported by the SME could impact on defence objectives.

The case studies used examples from fixed, shared and deployable CI. These three loose groupings where used to describe both the amount of control Defence has on an element of CI and the nature of the CI:

- Fixed CI examples include buildings, bridges and pipelines that remain in situ on base.

- Shared CI examples include transport chains, health care and communication channels used by both defence and the community. These are often operated by commercial entities.

- Deployable CI are the assets Defence uses whilst away from the usual home site, examples include mobile generators.

One of these case studies looked at the supply of energy to deployed forces. The transportation of liquid fuel to areas of conflict both in dollars and lives is very high (Hale 2013, Hickman 2008). The fuel logistics value chain currently has little opportunity for resilient approaches (Energy White Paper 2015, Klare 2001). The example considered here is the transportation diesel fuel to a deployed base. However technology options like photovoltaics could be explored to generate power at the site, reducing the liquid required and associated transportation costs. As one of many examples over the period of five years diesel -electric would use 250 Kg per MWh compared to $1 \mathrm{Kg}$ per MWh for a PV panel (Skryabin 2015). This and other options could be further investigated, if only to provide alternatives to diversify the set of power sources available to the deployed force.

Resilience is often a descriptor of the system (Meadows 2008, Mingers and Rosenhead 2004) and viewed as

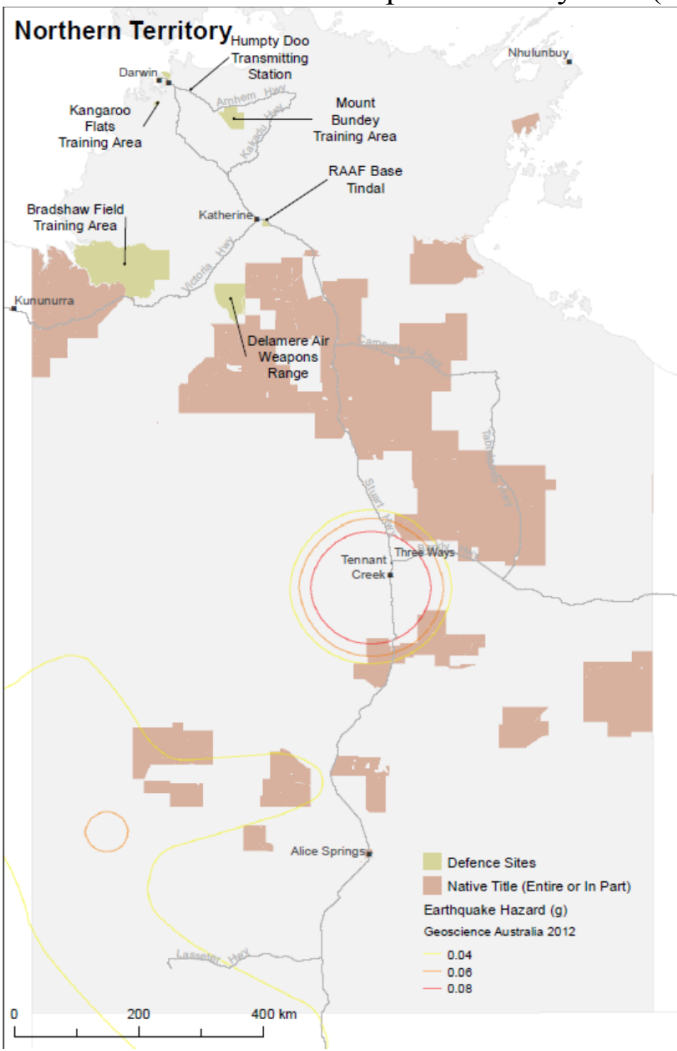
the ability of a system to recover or continue after a disruptive event. Alternative options and adaptations to business practices can be identified at the site with locally specific work practices and work-arounds. These work-arounds often exist to resolve irregular problems, but a) it's important to understand what might break those local solutions, and b) it's important for Defence as a whole to understand the stressors it is managing and when those stressors might cause 'breakage' (or breakdown of resilience).

During the workshops and site visits the SMEs were encouraged to identify where local conditions and subsequently the locally specific work practices existed. Often these local practices are documented in various lessons learnt or site specific documents (e.g. NT Government Reports 2015). The data from BOM and the known changes as a result of tropical storms validate this perspective. Showing that the local arrangements were based upon local knowledge and managing their local environmental consideration. Linking this BOM data with the SME survey data showed the impacts on these ADF sites (Figure 3). This allowed for some of the Defence CI vulnerabilities to be identified and communicated to senior decision makers. Of wider interest is that these local

Figure 5. Northern Territory (Geoscience Australia creek-shakes-again) 
arrangements did mask risks and made these unknown within the wider Defence organisation.

Natural influences were included in this study and were identified in the threats table (Table 1). These types of threat, from natural environmental conditions, like earthquakes, are not typically included in defence capability planning and no evidence was found identifying their inclusion in war games or lessons learnt databases. One of our areas of interest was the broader Darwin and Northern Territory region (Figure 5). This region has many defence sites and received many supplies from the southern states delivered along the Stuart Highway. This Highway passes through Tenant Creek (Figure 5). Tennant Creek is the only known Australian site to record earthquakes with higher than 6 magnitude, three of these occurred on 22 January 1988 within a few hours. Geoscience Australia identified two fault scarps about $35 \mathrm{~km}$ long and $8 \mathrm{~km}$ apart striking approximately east-southeast in the epicentral area with up to two metres vertical displacement, causing structural damage (buildings / roads / rail) within the region and severe warping of a major natural gas pipeline. Foreshocks started a year before the three large earthquakes, and thousands of aftershocks continued for a number of years, with the most recent significant ( $>3$ magnitude) tremor in 2013.

CI elements of energy (natural gas pipeline) and transport (rail / road) transect this geological zone known to suffer reoccurring significant seismic events. The Defence sites (Figure 5) are to some extent reliant on the Stuart Highway for transport and resupply logistics. There are documented impacts/disruptions and modification of defence activities due to disruption from these seismic events. These simple local issues are part of the reality at Defence sites. They can be chronic stressors, or form part of the set of impediments to a smoothly run operation. These local issues become chronic stressors, if they are never fully recognised, resolved, or prioritised, and they continue to erode the system efficiency. Examples can be found in almost every aspect of Defence CI. They introduce risks unknown to senior managers, particularly when the command chain is in a different location. These local issues can be opaque in the reporting systems as they are rarely recorded or have assessments undertaken. Collectively the chronic stressors can form a set of undocumented cascading risks.

The term graceful degradation was used to describe the set of risks where a Defence capability is planned to be replaced. However, Defence acquisition is measured in decades and delays are well documented. New capabilities do not always have the funding to replace an entire set of defence sites, the 'home base' is usually funded, and alternative sites are supported to lesser extents. So 'graceful' isn't really graceful, but rather an identification that the maintenance efforts are not keeping pace with the degradation and aging platforms - these are impending capability gaps, i.e., looming or latent vulnerabilities.

The case studies show some of the interdependencies and fragilities found within the Defence CI system and those additional fragilities lie in Defence's reliance on CI systems Defence doesn't own or maintain the "over the fence" components of the CI. Most of the case studies do not align into a single category of the CIPMA CI framework. Similarly the case studies did not fit within a single organisational management or command line within the ADO. The areas of interest for this work spanned lessons learnt from decades of exercises, site experience, changes to political direction and even changing climatic events. The boundaries for these case studies can fall beyond defence sites (Figure 6). For example, at some sites CI such as a bridge or access road were maintained by the local or state government. Their priorities are by necessity very different from those of Defence. Dual use or shared infrastructure with commercial entities, such as wharf authorities, introduces another set of complexities within the site. So while the relationship between Defence and external entities is often very positive, it needs to be noted that these relationships do fall within a contractual and potentially adversarial framework for reasons which may be entirely outside of Defence control.

\section{CONCLUSION}

Resilience is the ability of a system to recover or continue after an event; as such resilience and risk are often coupled together. CI disruptions are a risk which impact on Defence resilience. Understanding the activities defence undertakes and the internal and external events that can impact those activities provides a useful foundation to discuss the resilience of a region of interest or particular defence site.

This project was not designed to provide a comprehensive or systematic view of all CI vulnerabilities to Defence. What was possible was to provide Defence decision makers with case studies from across the sites of interest identifying the impact of past events on defence business. Defence must address the resilience of its sites and the systems that connect Defence to the community at those sites, if it is to continue to operate effectively in a changing world. Defence sites and Defence CI are part of a wider complex system of CI across Australia.

The case studies show the impact of CI on Defence business and operations. The continuity of Defence 
operations has been impacted by issues within the local infrastructure. Power outages are a simple, well documented example. Defence has developed various local work-arounds to ensure continuity of service during times of local power outages and the local arrangements reflect the frequency and severity of these occurrences. Sometimes these local outages are so frequent as to require the local work-arounds to be very well practiced it is worth investigating alternative options like solar power generation in these situations.

The study extracted data from many Defence inputs and external data sources. Combined together, this dataset was used to cross reference and provide traceable evidence to support the SME views collected at workshops and via surveys. This allowed SMEs to provide the actual impact that events had on Defence activities, and for those impacts to be categorised into themes, case studies and exemplars moving their views from hearsay to actionable evidence.

Within Defence, funding lines mirror command lines. So while this activity showed that Defence logistics, Estate and Preparedness all have separate funding and reporting lines, this was an expected outcome. As CI does not neatly fit within any given organisational or management area of Defence but still needs to be managed as part of the capability system, the impacts CI can have on Defence business appear to fall between these organisational disconnects.

This work was conducted to inform Defence senior decision makers on the impact if any CI on Defence business. By identifying a set of thematic groupings which highlighted the CI issues encountered by Defence sites and their impact on resilience of the site, the work demonstrated the impact of CI on Defence capability, and highlighted the importance of a resilient infrastructure.

\section{REFERENCES}

Ali I (2011) "Coexistence or operational necessity: the role of formally structured organisation and informal networks during deployments" ICCRTS International Command and Control Research Technology Symposium (ICCRTS) June 2011 DSTO GD 0646.

Ali I (2014) Methodological approaches for researching complex organizational phenomena. Informing Science: the International Journal of an Emerging Transdiscipline 17: 59-73.

Attorney Generals (2015) CIPMA data (TISN) and Journal of emergency management (AG Journal publication) http://www.ag.gov.au/NationalSecurity/InfrastructureResilience/Pages/CriticalInfrastructureProgramforModellingandAn alysisCIPMA.aspx and Attorney Generals http://www.tisn.gov.au/Pages/default.aspx

Attorney Generals CIPMA(2009) A review of national critical infrastructure protection ISBN: 978-1-921725-25-8 Journal of emergency management https://ajem.infoservices.com.au/ ISSN: 13241540

Attorney Generals (2015) Critical Infrastructure Strategy Plan 2015 ISBN: 978-1-925290-04-2 (Print) ISBN: 978-1925290-05-9 (Online) Critical Infrastructure Policy Statement 2015.

Australian Bureau Statistics (2015) Online databases http://www.abs.gov.au/ accessed 2014 - 2015

Berry,J.K (2007) Beyond Mapping III Topic 28: Spatial Data Mining in Geo-Business

http://www.innovativegis.com/basis/MapAnalysis/Topic28/Topic28.htm

Bureau of Meteorology (2015) BOM \& Climate data http://www.bom.gov.au/ and http://www.bom.gov.au/climate/ Creswell J (2009). Research design: Qualitative, Quantitative and Mixed methods approaches. Sage Publications: LA.

Defence White Paper (2015) http://www.defence.gov.au/Whitepaper/ReadSubmissions.asp accessed Nov 2014

Department of Industry and Science (2015), Energy White Paper http://ewp.industry.gov.au/ released 8 April 2015

Engineers Australia (2015) Publications http://www.engineersaustralia.org.au/

Geoscience Australia (2011) "Response". Geoscience Australia. 7 December 2011. Retrieved 20 June 2012.

http://www.ga.gov.au/ and Australian Flood Risk http://www.ga.gov.au/scientific-topics/hazards/flood Geoscience Australia http://www.ga.gov.au/news-events/news/latest-news/tennant-creek-shakes-again

Hale, Twomey (2013) Australia's Emergency Liquid Fuel Stockholding Update Oct 2013: Oil Storage Options \& Costs. Hickman A (2008). Assisting strategic analysis in an uncertain world. Security Challenges 4(1): 3-12.

King N (2004). Using templates in the thematic analysis of text. In: Cassell C and Symons G (eds). Essential guide to qualitative methods in organizational research. Sage Publications: London, pp 256-270.

Klare, M. (2001) Resource Wars: The New Landscape of Global Conflict (Owl Books, 2001), pp. 122-123

Mazourenko E and Jobst M (2014). A Theory Based Framework for Critical Thinking in Defence Planning and Assessment. Australian Defence Force Journal 193: 77-90.

http://www.adfjournal.adc.edu.au/UserFiles/issues/193\%202014\%20Mar_Apr.pdf

Meadows D (2008) Thinking in Systems: A Primer Chelsea Green Publishing, 2008 ISBN1603581480, 978160358148

Mingers J and Rosenhead J (2004) Problem structuring methods in action. European Journal of Operational Research 152(3): 530-554.

Northern Territory (2015) Government Services Reports (accessed Aug 2014 - June 2015) NT Government Services

Reports http://www.powerwater.com.au/networks_and_infrastructure

Punch K (2005). Introduction to social research: quantitative and qualitative approaches. Sage Publications: London.

Skryabin I. (2015) Australian National University: Energy Change Institute, Professional Course June 2015 